\title{
19. On the journey of transforming transport systems for human scale cities
}

\author{
Miloš N. Mladenović, Elias Willberg, Tuuli \\ Toivonen and Karst T. Geurs
}

The ultimate end is not knowledge, but action. To be half right on time may be more important than to obtain the whole truth too late. (Attributed to Aristotle)

\section{SELECTED FINDINGS FROM PART II AND RELATED REFLECTIONS ABOUT HUMAN SCALE URBAN TRANSPORT SYSTEMS}

Without any intent of conveying all the messages from the 18 preceding chapters, here we would like to summarize some selected findings in relation to the need for transformation of urban mobility systems. Part I has brought us a handful of important insights for moving away from the Homo economicus model and embracing the multidimensionality of the mobile human being in the city. With that in mind, the first point ahead, as Chapter 2 informs us, is that we need to allow for multiple meanings of what human wellbeing is and how it can be achieved through built environment and policy interventions. Current conceptions of subjectively experienced wellbeing grounded in hedonic and eudaimonic perspectives cannot be always taken as universally applicable in the domain of urban transport. Understanding of wellbeing for the individual has to be put in the context of a socially contracted and constructed common place that a city is, where furthering selfish benefits for some, such as allowing the use of large passenger cars, should not be allowed to the significant detriment of others. Drawing from findings of Chapter 3, we have to recognize that our cities have often provided a significant discrepancy in an essential mode for human wellbeing: walking. All too often, walkability is only a feature of city centres, and the most economically deprived people face a lack of pedestrian facilities, further restricting their use of public transport. Furthermore, Chapter 2 underlines that since wellbeing has multiple meanings, this requires us to move away from straightforward and linear causalties, and to extend our 
understanding towards relational and co-constitutive nature of human beings in the urban environment.

The findings from Chapter 4 and Chapter 5 allow us also to return to the often-used assumption of 'average' humans whose primarily commuting needs in the morning and return from work is what we need to mainly care about in shaping our transport systems. Aiming to achieve a modal shift away from private cars for commuting trips requires us to further expand the understanding of Homo mobilis. Such expanded understanding is essential to help us make better decisions regarding planning public transport systems. At the beginning, as Chapter 4 informs us, we should recognize that commuting is not simply a functional activity, where changes in accessibility can by themselves influence breaking out of the unsustainable habit of car driving. From the stance of rehabituation processes of everyday activities in the context of the Global South, we see that income and poverty aspects are important for habit preservation in mode choice. In particular, low-income individuals depend on public transport, regardless of their accessibility conditions; while high-income individuals do not use public transport, for reasons that are not associated with accessibility. Similarly, gender issues are at the forefront, where women are generally more likely to use public transport, ultimately leading us to ask the question of masculinity norms associated with car use. Thus, the question of distributive justice and burdens on particular least advantaged groups is something we have to connect back to transformation of our mobility-related norms and values. Certainly, an additional relationship to include is the one between commuting and work-life satisfaction, an essential aspect of human wellbeing, as Chapter 5 underlines. In addition, we have to ask a question: where should we look for improvement to our public transport systems beyond the immediate focus on the least advantaged? These two chapters point towards urban areas with a middle-income population. Besides extending operating hours to cater for diverse commuting needs throughout the day, an important aspect of focusing also on the middle-income population is further habitual public transport use support, which can tip the balance of deeper norms in the long term.

Turning our gaze towards the elderly, Chapters 6 and 7 provide us with an interesting set of similarities and complementing contrasts between the south and north of Europe. Despite the obvious climate and urban form differences between Portugal and Norway, the concern for wellbeing of a growing population of the elderly is something in common. As having an active lifestyle with physical activity and social interaction is essential for the wellbeing of elderly people, we need to find ways to enable and encourage moving away from car-dependent everyday mobility. On the one hand, Chapter 6 argues that we need to understand the classical integration of walking and public transport through the needs and preferences of the elderly. On the other hand, Chapter 7 argues that we should also design new mobility sharing services, such as car 
sharing, through the perspective of the elderly, as they should enable an active lifestyle. To improve our understanding of the ageing population on the move, we need to look for functional factors such as lack of infrastructure or its deteriorated state of maintenance, but also to understand the relationship between material infrastructure and competences and meanings. One important window of opportunity for behavioural change is a dilution of meanings associated with private car ownership happening over recent years. Such a change in meaning stems partially from environmental concerns for future generations, as well as from reducing competencies for car driving itself that elderly people experience due to cognitive or even economic reasons. Thus, even with the focus on a specific group of people, Chapter 7 shows us how understanding interdependencies between infrastructure-competences-meanings, understood through application of social practice theory, would pragmatically lead to highlighting additional aspects for improvement from the narrow definition of functional mobility. For example, further understanding and shaping competences and meanings in relation to infrastructure would lead us to look for possibilities on how to improve public transport driver training, how to improve security through non-digital and lighting solutions, how to improve the visual appearance of transport vehicles and the surrounding environment, and how we use opportunities for combining learning and social interaction across generations in designing urban mobility services.

\section{SELECTED FINDINGS FROM PART III AND RELATED REFLECTIONS ABOUT RESPONSIBLE INNOVATION PRACTICES FOR HUMAN SCALE CITIES}

As the urban mobility landscape is undergoing a period of rapid and dynamic pace of new services emerging and being experimented with, there is certainly a need to draw some key lessons from Part III of this book. As these technologies are in formation, one of the essential challenges is how to adequately take into account users' perspectives about the hypothetical future choice situations. With a focus on Mobility-as-a-Service, Chapter 8 provides an example of stated adaptation methodology, useful for understanding the mode choice adaptation process of travellers in response to a hypothetical subscription. Such methodology should be particularly useful for reducing the often conflicting hypothetical and cognitive bias in surveying stated preferences. Expanding the focus on human scale further, Chapter 9 informs us about discrepancies between people's and technology developers' expectations for vehicle automation in rubber-tyred public transport. In this particular case, people place a high value of both safety and security on board the vehicle, as most of them would prefer to have a human steward on board. Such a conclusion can be found in many previous attempts to automate public transport vehicles even 
for rail-based systems, as in practice many such vehicles still do have stewards on board. Thus, we take this as a firm warning that the technology is still premature and unsatisfying, despite the great desire to reduce operating costs in public transport systems. Underlying the message against technological determinism, Chapter 9 ends with an encouragement for the further embrace of design thinking in developing new transport services. Similarly, Chapter 9 recognizes that planners and policy-makers have the responsibility to steer mobility innovations. Ultimately, extending from findings in these chapters, our suggestion is that developing responsible processes requires moving away from understanding humans as merely the adopters of technology, but rather understanding them as learners over time, and eventually even as co-creators of the technology itself.

Having in mind that innovation processes often require experimentation in the urban commons, in order to help build a transition pathway from niche to regime, Chapter 10 provides important lessons in relation to supporting behavioural change. The conclusion that this chapter reaches is that monthly choice challenges can be an effective way to encourage cycling behaviour. In particular, experimentation often involves a question of how difficult challenges should be, and this research concludes that it is important to let users choose the challenge level, but that even easy challenges do not necessarily yield less behavioural change. Such findings further underscore the communitarian aspects of human beings, who also appreciate being part of a larger endeavour in and of itself. However, we have to recognize that innovations in mobility systems often face the challenge of need for larger-scale systems integration, in contrast to some other domains of digital innovation. In Chapter 11 this brings us to a neighbourhood-scale integrated mobility concept, packaging a range of mobility measures and services. The conclusion here is that measures and services should not be observed in isolation to understand their impact, but that their combination can also have undesired effects. Moreover, this research also informs us that such combination is not always based on actants aligning their goals, but they could actually be in contradiction even if there is an agreement about some measures. Thus, this chapter leads our reflection to further question of conflicts of interest, challenges in cooperation and communication, and the need for new integration actants established in governance networks.

\section{SELECTED FINDINGS FROM PART IV AND RELATED REFLECTIONS ABOUT POTENTIALS FOR DEVELOPING PLANNING PROCESSES FOR HUMAN SCALE CITIES}

Part IV of the book provides a set of lessons focused on urban and transport planning processes. The common thread across Chapters 12,13 and 14 is that 
planning our cities to enable travelling by cycling is inclusive of all human scale transport modes. From here, we would further argue that, similar to the point made in Chapter 12, we should not be holding out hope for more digital interventions that further strengthen car dependency. In addition, Chapter 12 furthers systems thinking approach to the application of street design, where most urban settlements could be set up for cycling, relying on positive feedback loops. This understanding of cities as complex systems is in line with the previous arguments, especially those from Chapter 2. Pragmatically, planners need to embrace the dynamics of cycling network growth when prioritizing actions, focusing on locations where many short trips begin or end, and focusing on completing unconnected parts of the network before expanding coverage further away. As some have argued before, Chapter 13 recognizes that we have not been developing many planning support systems for cycling-related decisions, which is an even greater problem for resource-constrained cities that lack existing infrastructure, cycling norms and organizational capabilities. Thus, one of the key aspects we need is development of both scientifically robust and usable planning tools that would support making decisions of where to begin any cycling investments at all. As planners would often need to defend their choices for such investments in front of policy-makers, they need higher chances for initial success if they can gain support for further long-term strategy development of the city-wide network. Geographic information system (GIS)-based tools can thus be useful in accounting for spatial measures while also providing visual outputs for communicative sessions. In addition to useful tools using existing databases of population, Chapter 14 argues that we should do a better job in collecting quantitative and qualitative data from various novel and conventional sources. However, 'more data' is more easily said than done, and thus we need a careful reflection on strengths and weaknesses in finding the most useful data for the given problem at hand. Such reflection on usefulness goes hand in hand with considerations of data availability, representativeness, and associated ethical challenges such as privacy.

Expanding our scope of potential data sources, Chapter 15 argues for a greater inclusion of citizen-based data collection. This is certainly not only about additional data sources, but also poses a question of the roles of citizens in planning processes. Thus, if we are to remain constrained to the domain of better expert decisions, we would run into a conflict with value diversity and ultimately a need for democratic nature of built environment planning in general. Focusing on place-based web questionnaires, Chapter 16 provides reflections for developing public participation activities in planning processes, if we are to understand further existing mobility behaviours or perceptions on proposed alternatives. Here, the question of data validity expands to questions of problem legitimacy and the need to support communicative planning activities that should be based on transparency and accountability. Pragmatically 
speaking, although initially this might be a large step, including people in participatory processes can only benefit the organization of planning processes in the long term. Besides understanding existing mobility behaviours or perceptions on proposed alternatives, Chapter 17 provides a framework for further engagement of a wider range of stakeholders in the development and evaluation of plan alternatives. When organizing such activities, urban residents can be included into different groups to integrate their diversity into evaluation. As a result, participatory planning activities should not solely benefit the learning of planning organizations, but can also be an investment into long-term civic learning and positive engagement. Reflection on participatory planning activities inevitably relates to the institution of modern democracy, whose strengthening is something that Chapter 18 can help us to dive into. As also highlighted in Chapter 11, the foundation of modern democracy is an irreducible web of common and conflicting interests stemming from societal pluralism. Especially conflicts of interest are obvious in long-term mega-projects of urban infrastructure planning, such as the Metro of Lima. Here, the constraint of funding sources does not make things easier by itself, but planning is usually an activity of dealing with constrained resources and technical possibilities. What is more or less common in planning processes is the level of trust established in the governance networks. Such trust-building processes require some essential aspects, such as creating conditions where a large proportion of the population can have first-hand experience of the changes in transport service. What we can further learn from Chapter 19 is that trust-building also requires not falling into the trap of perceiving negative news in the media solely as a threat. Sanctioning discourse is not the way out of the undeniable dimension of antagonism in modern pluralistic societies. Potential for emerging conflict is what democratic politics involves. The challenge then becomes how to legitimize conflicting interests, and create conditions for adversaries to co-create decisions, even if not having agreeable views. Participatory planning implies that the governance system has to be able to handle such - for some, paradoxical - tensions, allowing for an unquestionable right to present and defend views, but aiming for partly consensual decisions, acknowledging that some differences might remain unaddressed.

\section{THREE KEY DOMAINS OF CHANGE FOR THE ONWARD JOURNEY OF TRANSFORMING URBAN MOBILITY SYSTEMS}

The chapters in this book have provided us with a range of findings from around the world, from Peru, Brazil, the United States, Canada, Portugal, the United Kingdom, Germany, the Netherlands, Norway, Sweden, Finland, Australia and New Zealand. These lessons have been based on a range of meth- 
odological approaches, from statistical and GIS analysis to well-supported and logical critical argumentation. It would not do a complete favour to all the individual chapters if we simply tried to list all of their suggestions for future action. Instead, in this section, we want to make a first step towards a more networked understanding, by establishing a framework for inspiring responsible future-making. In line with the opening quote from Aristotle, our ultimate concern is on the side of acting, despite all the importance of knowing.

Taking our proposal as a starting point for further learning and action, we propose three key domains of change: (1) changes in actions and virtues of diverse actants involved in future-making; (2) changes in governance and processes of these networked actants; and (3) change in the core conceptualizations used in understanding urban mobility.

Starting with the changes in actions and virtues of diverse actants involved in future-making, we would like to briefly reflect at the level of actions and virtues for diverse actants responsible for future-making, ranging from planners to innovators and academia itself. Several chapters in the book have highlighted the importance of wellbeing and diversity of the meaning of happiness, ultimately related to the richness of human everyday experience, from which we can draw lessons for changes in actions and virtues. For example, Chapter 2 has argued for experimenting with more context-sensitive, relational and process-oriented perspectives on human wellbeing and everyday mobility. Such experimenting is needed both in practice and in academia. Emphasizing such experimentation actions is especially important if we are to talk not just about human needs but also about changing human wants, and ultimately about behaviour in the urban environment. Our future actions should further seek to uncover many interdependent aspects of the routine everydayness of urban mobility practices. We can find many such concrete recommendations in Part II's chapters, including aspects such as more diverse population segments, safety and comfort, gender, age, employment, poverty, and long-term physical and mental health. In light of the ongoing COVID-19 pandemic, we should further draw lessons for anticipated similar events in the near and distant future. Future studies would benefit from even more mixed-method and longitudinal datasets, furthering the spirit of transdisciplinarity at the level of all future-making actors. In addition, we should act upon formalizing as many as possible of those methods in open access planning or innovation support tools. Here, it will not be enough to solely focus on humans in the city for future studies, but we in both practice and research need to pay more attention to diverse and changing experiences and responsibilities of humans in hybrid institutional networks. As we will argue further below, this is not just about a pragmatic purpose of furthering action research activities, and evolving redistribution of roles and responsibilities for future-making. Just as we would argue that we need to shift away from the narrow model of the human being on 
the move in the city, a similar shift has to happen with our model of humans in the organizational processes. For such a shift to happen, there is an essential need to nurture a virtue of mutual care and empathy between people both in practice and in academia. Just as we should not treat humans on the move in the city as solely objects of study and change, so we should not fall into the same trap in our mutual relations involving academia and practitioners. Nurturing virtues of care and empathy will have a true power of developmental action, co-creating essential conditions of trust and support for systemic change needed in transforming our urban mobility systems.

Turning to the second key domain, changes in governance and processes of these networked actants, we would like to briefly reflect on interdependencies between organizational networks, processes and visions. Organized actions in changing our built environment emerging around the world at the time of the COVID-19 pandemic have shown us that our organizations are capable of adapting to shocks. However, can we achieve permanent structural change, both in our cities and in our future-making organizations? As the first step of structural change, we should certainly aim at having further development and use of adequate planning support tools for everyday mobility centred on integrated walking, cycling and public transport planning processes. Similarly, we need to improve organization-level data collection and sharing processes, balancing longitudinal accumulation and sensitiveness with privacy through consent and access restrictions, and explicating the used spatio-temporal and demographic attributes on the aggregate level when possible. Academic organizations should here act as role models, responsibly opening their own databases as much as possible. Similarly, academic funding bodies and publishing instruments should increasingly urge opening of data and transparency of methods through sharing of analysis or processing codes. In addition, it is important to continue responsibly testing various emerging technologies for urban mobility transformation, and carefully evaluating their priority for implementation in the wide range of technological actions we already have at our disposal for urban transformation.

Besides these aspects, if we are to talk about crafting human scale cities around the world, we have to account for governance contexts on a much deeper level of organizational processes and ideologies. Thus, if we are to be advocating for initiating and sustaining behavioural change in urban mobility, we have to aim for behavioural change in our own organizational processes. For such organizational behavioural change, we have to relate it back to knowledge integration and organizational learning processes. For enabling such learning, we need to increase the amount of comparative studies conducted across societal and governance contexts, relying on expert surveys and focus groups, simultaneously using analytical methods for understanding spatio-temporal mobility patterns. In addition to comparative studies, we also 
need more longitudinal studies of dynamic patterns of interactions between diverse urban actants, if we are to learn from the structures and patterns of their complex interactions. As we have already seen in some of the chapters in Part IV, many unanticipated ways in which these multi-actant processes unfold can enrich our understanding. Following the lines of open science experimentation, we need further processes to widen the set of participating actants, further democratizing the collective imagination of both the built environment and emerging technologies. Starting with further understanding of why we have the potential selection bias in public engagement, such processes have to aim for building bridges between academic and practitioner activities. However, we should not be under the illusion that we can immediately have synergetic interorganizational ideologies in relation to future-making. Such mixed-actant processes have to depend on successful mediation of differing views, not falling into the trap of sanctioning fierce debate. This would certainly go against the pluralism of our societies, and would be in direct conflict with previous statements on the plurality of knowledge. Instead of antagonistic fear, we have to be comfortable with friction and the agonistic process of trust-building, where if actants are pointing out the challenges, they are not doing so to hurt, but rather to construct.

Nonetheless, we also recognize that change is not easy and often hurts. Looking in the mirror ourselves, we have to acknowledge that academic institutions also need to continue thinking about new professional roles and educational needs beyond existing disciplinary silos and identities. For that, we need direct institutional incentives for more mixed-methods, transdisciplinarity and action research, further normalizing the integration of social science knowledges. As we have seen clearly in some chapters, new perspectives (for example, social practice, political economy, complexity theory) can be rather useful in deepening understanding. Furthermore, as was experimented with during the Network on European Communications and Transport Activities Research (NECTAR) 2019 conference, future NECTAR and other previous academic conferences should be among these associations for testing new activities and agendas. Furthering research-practice collaboration and co-creation takes years and a lot of trial and error. Nonetheless, this will certainly be an important step for the future of NECTAR in both responding and actively steering the ongoing societal transformation.

Ending with the last key domain, change in the core conceptualizations used in understanding urban mobility, this book argues for the necessity of changing our anchoring conceptualizations. As already mentioned in Chapter 1, our overarching suggestion is that our new anchor point for knowledge-building should be a human scale city. It is to serve as a boundary object, allowing us to readjust our scale in understanding the multidimensional and ever-changing Homo mobilis existing within a multilayered and ever-changing urban envi- 
ronment. Re-anchoring on a human scale city, we recognize the power of language in relation to thinking and identity at the level of individual learning, and at the level of organizations, in relation to organizational cultures and imaginaries. Moreover, such re-anchoring provides us with several points for hopeful thinking and action. We hope that this book has shown the potential power that such ideological conceptualization has in expanding the horizon of imaginable futures, constructing meanings of what built environment, technology or policy could be. We hope that this concept will help us in embracing the irreducible emergence of mobility commons, as ultimately a social-technicalenvironmental system. We also hope that it will help us to embrace the necessary complexity of social justice frameworks that can look beyond an opposing dialectic between utilitarian and distributive justice foundations. Hand in hand with those, we hope that such re-anchoring will be helpful to clarify further the moral limits of transport as a societal good, and application of solely economic principles for its evaluation. However, having in mind the relational beings that humans are, we want to clarify that human centricity in our understanding is not narrow anthropocentricity. We do not suggest that we should only consider narrowly defined human psychological or existential needs, and treat the environment as a separate entity or even just a resource to be managed. In fact, such a misconception is at the heart of our abuse of ecological systems in the past two centuries following the industrial revolution. Thus, if we negate our relational existence within other networks of life, it would not just be a question of injustice towards those beings, but it would essentially lead to a degradation of both our moral capacity and our authority. Such abuse raises the difficult challenge of our very collective survival on this bounded planet.

Returning to the Aristotelian idea also made in Chapter 1, that knowledge and action are one, we have to avoid falling into the trap of post-Enlightenment rationalist thinking that is still prevailing in transport studies. Just as there are many potential actions above, so there are many different kinds of knowing, and this knowing as a process of future-making is distributed across diverse actants in governance networks. Thus, we cannot claim that we have presented a complete alternative to the path-dependent knowledge-action structure of urban transport systems. Essentially, pretending to provide an ultimate structure of knowing would also go against the idea of pluralism of humanity. After all, each human has a slightly different cognitive model, just as the same is true for each planning organization. There is no one single essence, no one single knowledge-action structure. However, this does not diminish our stance in relation to relativism or, even worse, irresponsibility falling into the pitfall of determinism. Quite the contrary, it requires an even greater sense of responsibility and commitment for future-making. To question our own sense of responsibility and commitment, we have actively reflected on the potential for blurring the roles and boundaries between research and practice. 
Pragmatically, our current answer is that we need more people with a dual cross-organizational role, to serve as knowledge integrators. This would be an important first step in reconceptualizing future roles and responsibilities by opening up possibilities for new identities. However, we hope that the chapters of this book will serve as inspiration for further encouragement of commitment to sustainable futures. Ultimately, we hope that our reflections presented here have shown a firm sense of the very commitment that such alternative futures are possible, and that for enabling those futures, the change has to start from all of us, in both practice and academia. 